\title{
23-year experience on diagnosis and surgical treatment of benign and malignant cardiac tumors
}

\author{
Anna Kośmider ${ }^{1}$, Ryszard Jaszewski², Anna Marcinkiewicz², Karol Bartczak², Jerzy Knopik ${ }^{2}$, \\ Stanisław Ostrowski
}

${ }^{1}$ Military Teaching Hospital, Veterans Central Hospital, Medical University of Lodz, Poland

${ }^{2}$ Cardiac Surgery Clinic, Chair of Cardiology and Cardiac Surgery,

Medical University of Lodz, Poland

Submitted: 27 October 2010

Accepted: 31 January 2011

Arch Med Sci 2013; 9, 5: 826-830

DOI: 10.5114/aoms.2013.38677

Copyright @ 2013 Termedia \& Banach

\begin{abstract}
Introduction: Although myxoma is the most frequent cardiac tumor, other conditions should be taken into consideration in the differential diagnosis. Transthoracic echocardiography (TTE), followed by transesophageal echocardiography (TEE) remain the principal methods for cardiac tumor screening and visualizing. The aim of the study was to compare the diagnostics, surgical treatment and prognosis of malignant and benign cardiac tumors.

Material and methods: From 1986 to 2009 there were 121 patients with cardiac tumors operated on in the Cardiac Surgery Clinic of the Medical University in Lodz. Patients were referred to surgery mainly on the basis of the TTE and TEE image. In 4 cases valvular prosthesis implantation or valve repair were carried out. Patients remained under long-term observation in the Cardiac Surgery Outpatient Clinic.

Results: Myxoma was diagnosed in 114 cases. Malignancies were discovered in 7 cases. The left atrium was the most frequent localization. The echocardiographic image differed significantly in benign and malignant tumors. The postoperative period was complicated by embolic events or myocardial infarctions. Only malignant tumors were associated with mortality due to cardiovascular events. The survival for malignant tumors was significantly shorter.

Conclusions: Short and long-term results of operative treatment are very good for benign tumors in contrast to cardiac malignancies. The TTE and TEE image can be very significant in the final diagnosis.
\end{abstract}

Key words: transthoracic echocardiography, transesophageal echocardiography, myxoma, sarcoma.

\section{Introduction}

Heart tumors are diagnosed only in 0.001-0.28\% autopsy cases [1]. Seventy-five percent of cardiac tumors are benign. Myxoma is the most common one, representing over half of them [2]. Among cardiac malignancies angiosarcoma is the commonest [3]. Regardless of their malignancy heart tumors create an unspecific clinical presentation. Their intracardiac localization within the heart chambers or the heart layers results in a different level of hemodynamic impartment. No less important is the mobility of the tumor or the presence of the peduncle. The whole impacts

\author{
Corresponding author: \\ Anna Kośmider MD, PhD \\ Military Teaching Hospital, \\ Veterans Central Hospital \\ Medical University of Lodz \\ Lodz, Poland \\ Phone/fax: +48 426331558 \\ E-mail: \\ anna.adkosmider@gmail.com
}


the presence of complications, mainly embolic incidents and heart failure. The method of choice to precisely diagnose the intracardiac mass is transthoracic echocardiography (TTE), which can be widened by transesophageal echocardiography (TEE) in some cases. The differential diagnosis must concern not only the variable types of neoplasms, but also lipomatous hypertrophy of the atrial septum, the presence of a thrombus in the heart chambers or infective endocarditis. Comprehensive echocardiographic evaluation of cardiac tumor is associated with a further indication for surgery or conservative treatment.

The main purpose of the study was to compare the diagnosis and treatment of benign and malignant tumors of the heart, as well as their prognostic assessment.

\section{Material and methods}

From 1986 to 2009 in the Cardiac Surgery Clinic of the Medical University of Lodz there were 121 patients operated on due to a cardiac tumor. The analyzed population was comprised of 81 women and 40 men. These were patients aged $26-77$. The average age was $53 \pm 15.2$ years. Transthoracic echocardiography was the method of choice in the diagnosis and monitoring of the treatment of heart tumors. When the acoustic window was very difficult or the TTE image suggested an infiltration of the mitral leaflet or lateral left atrial wall, TEE and intraoperative transesophageal echocardiography were performed.

Patients were referred to elective surgeries. The operations were carried out under extracorporeal circulation (ECC), from a standard access through median longitudinal sternotomy. Protection of the heart was obtained by cold, crystalloid cardioplegic solution, given to the aortic bulb. The ECC was carried out in normothermia or in hypothermia in selected cases. The aortic cross-clamp lasted from 20 to $80 \mathrm{~min}$ (average $50 \mathrm{~min}$ ). The total extracorporeal circulation ranged from $30 \mathrm{~min}$ to $110 \mathrm{~min}$ (average $70 \mathrm{~min}$ ). The arterial cannula was inserted into the ascending aorta, before the brachiocephalic trunk. The venous cannulae were inserted through the right atrium into the venae cavae inferior and superior. During the operation the intracardiac tumor mass was excised. In each case the removed biological material was histopathologically examined. In selected cases the surgical treatment also included implantation of a mitral prosthesis or mitral ring annuloplasty.

Within a week after surgery the early postoperative effect was assessed by TTE. The examination was repeated between the $7^{\text {th }}$ and $14^{\text {th }}$ day of hospitalization in order to re-evaluate the patient's state before being discharged from the hospital.

The patients were included in a long-term follow-up ranging from 1 to 15 years, average 7 years.
The patients were under ambulatory care in the Cardiac Surgery Outpatient Clinic. The physical condition, electrocardiography (ECG) and TTE were assessed.

\section{Results}

In our clinic benign tumors accounted for $94 \%$ of diagnosed cardiac tumors and myxoma was the only diagnosis. Among the primary malignancies sarcomas were the only ones observed (Table I).

The TTE examination usually disclosed a large tumor (average size was $4.5 \mathrm{~cm} \times 3.8 \mathrm{~cm}$ ), polypous, of a heterogeneous structure, and encapsulated with the pedicle near the fossa ovalis of the interatrial septum. Typically, it was a mobile structure, impeding the left atrioventricular ostium, and clinically presented as a stenosis in $74 \%$ or compressing the mitral valve leaflets, causing its insufficiency in $90 \%$ of cases. This was a typical presentation of benign tumors, found in 114 cases, of which 101 were localized in the left atrium and the remaining 13 in the right atrium. The right atrial tumors presented tricuspid valve regurgitation in 3 cases and tricuspid stenosis in 1 case. Myxoma was the only diagnosed benign tumor of the heart. In 4 patients there was recorded an image of left atrial tumor, but in a different location, near the posterior leaflet with its thickening, or round the postero-lateral wall of the left atrium with its thickening without the pedicle and encapsulation. In 2 patients the tumor showed invasive growth. In the first case the structure was infiltrating the left upper pulmonary vein. In the second case the mass was localized in the left ventricular outflow tract, giving the symptoms of aortic stenosis, and partially located in the left atrium under the anterior leaflet, which was thickened as well as its basic part of the interventricular septum. Histopathologically, in these 2 cases the malignant neoplasm was confirmed. In the total study population, primary cardiac neoplasms or metastases were established in 7 cases. In our clinic the malignant tumors (average size $4.5 \mathrm{~cm} \times 3.8 \mathrm{~cm}$ ) were smaller than the

Table I. Malignant cardiac tumors diagnosed and treated in the Clinic of Cardiac Surgery of the Medical University of Lodz during 23 years of experience

\begin{tabular}{|ll|}
\hline Variable & Patients \\
\hline Primary cardiac sarcomas: & 1 \\
\hline Leiomyosarcoma & 1 \\
\hline Myxosarcoma & 2 \\
\hline Fibrosarcoma & 1 \\
\hline Siposarcoma & 1 \\
\hline Thymoma & 1 \\
\hline Non-small cell lung carcinoma & \\
\hline
\end{tabular}




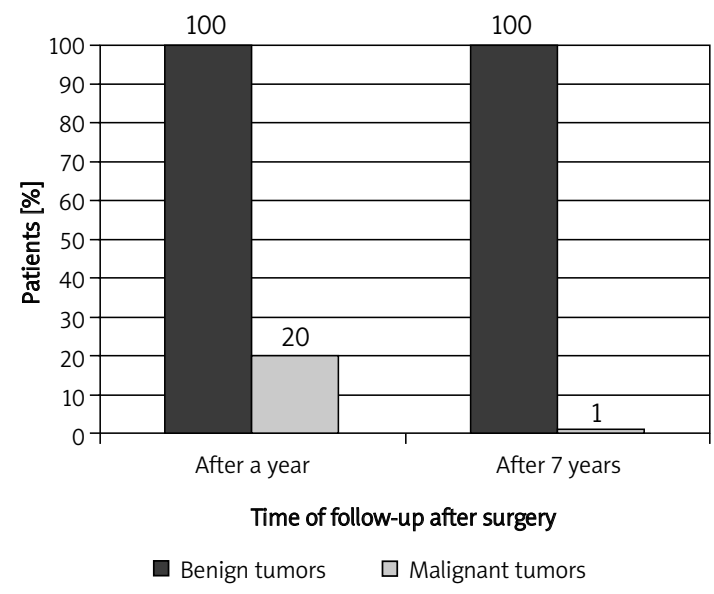

Figure 1. Comparison of 7-year follow-up in patients with benign and malignant cardiac tumors, operated on in the Cardiac Surgery Clinic of the Medical University of Lodz

benign tumors (average size $5.9 \mathrm{~cm} \times 5.1 \mathrm{~cm}$ ), of a more compact structure, unpedicled, closely fused with the surrounding structures of the heart, and thus had lower mobility and a greater tendency to block the venous ostium, which resulted in very high flow gradients. The group with malignant tumors was younger. In 107 patients the tumor was localized only in the left atrium. One case concerned the left atrium and left ventricle. In 13 cases it was located in the right atrium. Within the tumors of right-side localization there were no malignancies noted. In all cases of benign tumors a radical resection was achieved. In 2 cases prosthetic valve was implanted because of the valve involvement and damage by the tumor growth. In 2 cases mitral valve repair due to regurgitation was performed. In the early postoperative period complications such as embolic incidents in the central nervous system (CNS) in 5 patients or myocardial infarction in 1 patient were reported.

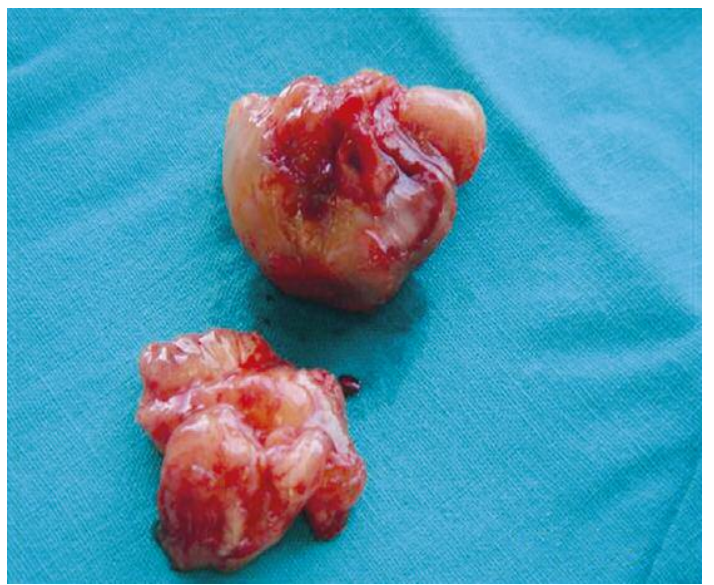

Figure 2. Intraoperative image of a malignant tumor, situated in the left atrium
During 7-year follow-up local recurrence was reported in 3 patients with benign tumors. There was no cardiac mortality. In comparison, in 5 patients with malignant tumors recurrences occurred within a period of less than 6 months. In 1 case early recurrence on the $10^{\text {th }}$ day after surgery was diagnosed. In case of malignancies long-term prognosis was very bad in our clinic. Six patients died of cardiovascular diseases within 1 year. Only 1 patient, after several cycles of chemotherapy and radiotherapy, during one and a half year of observation, is in a stable condition (Figures 1-5).

\section{Discussion}

Primary cardiac tumors occur much less frequently than metastatic lesions [4]. Based on numerous reports from autopsy, it is estimated that there is a 3-100 or even 1,000 times more frequent presence of metastases in relation to the primary lesions [4-6]. Patients with tumor of the heart long remain asymptomatic. Similarly, our patients were initially slightly symptomatic, but in almost $50 \%$ of patients an initiating symptom was an embolic incident to the central nervous system. In the course of tumor enlargement, in the majority of cases there was noticed an unspecific clinical presentation of systemic symptoms (weight loss, subfebrile states with articular or muscle pains, anemia, dysproteinemia, increased C-reactive protein), cardiovascular symptoms (congestive heart failure, dyspnea, easy fatigue, cardiac arrhythmias, pulmonary edema, cardiac murmur depending on the body position) and relatively frequent embolic episodes (relatively often associated with myxomas, 30-50\% of cases) [6-8]. Similarly, our clinical analysis was strongly dominated by benign tumors - myxomas. Malignant tumors were among the minority ( 7 to 121 cases). There were not noted other forms of benign tumors such as lipoma, fibroma, fibroelas-

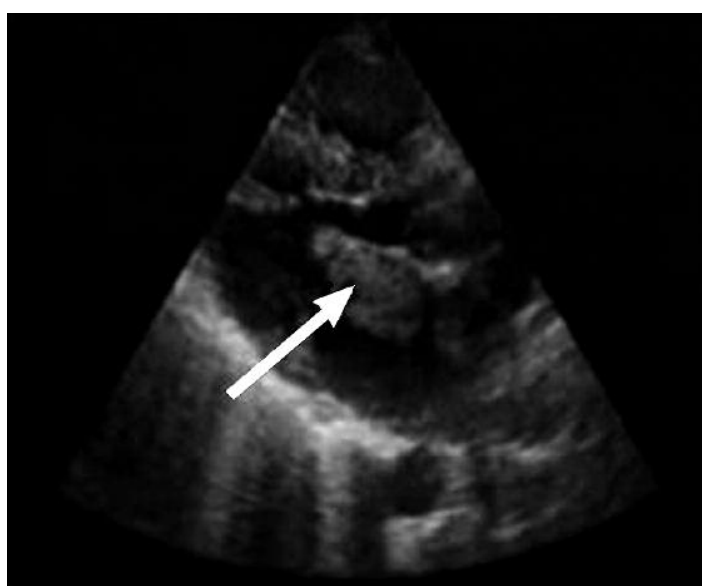

Figure 3. TTE image of the above shown malignant cardiac tumor 


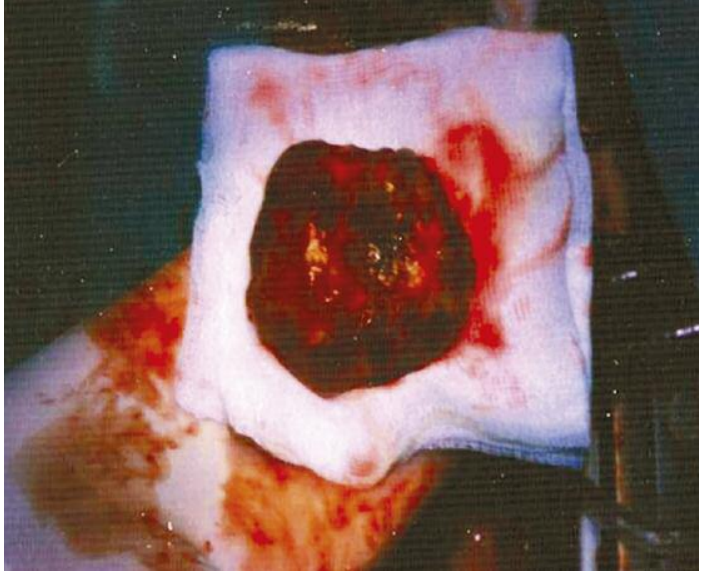

Figure 4. Intraoperative image of myxoma

toma, leiomyoma, lymphangioma and others, relatively frequently present in clinical observations, but mostly in younger populations. Myxoma may be located in each cavity of the heart or on each valve; the majority (70-80\%) occurs in the left atrium, $15-20 \%$ in the right atrium, $4 \%$ in the right ventricle, $4 \%$ in the left ventricle, and both atria are involved in $2.5 \%$ [9-11]. The study group was dominated by the presence of myxoma in the left atrium followed by right atrium localization. Other locations were not identified. In other clinical reports on a large clinical material dominance of the left atrium was up to 94\% [12]. Left atrial myxomas are usually pedunculated tumors with high mobility, extending from the interatrial septum near the fossa ovalis, extremely rarely from the atrial free wall. Posterior atrial wall localization usually indicated the malignant nature of the lesion. Ventricular myxomas are almost always situated within the free wall of the ventricle [13]. The size of myxomas varies, ranging from $1 \mathrm{~cm}$ to $15 \mathrm{~cm}$, usually $5-6 \mathrm{~cm}$. The basic and most widely used method for diagnostic detection of the lesions in the heart muscle was TTE. In diagnostically ambiguous cases, TEE was helpful, both in our study and in other reports.

Using both diagnostic methods allowed us to differentiate preoperatively the great majority of myxomas, which then could be fully confirmed anatomopathologically. In some cases, we used computed tomography (CT) (2 patients) and magnetic resonance (MR) (4 patients), which added important characteristics to the differentiation of myxomas, thrombus, or infiltrative growth. Magnetic resonance can be especially helpful in diagnosing intra-cardiac mass mainly due to superior tissue contrast or discrimination of different tissue characteristics [14] and CT has almost $80 \%$ sensitivity and $100 \%$ specificity in distinguishing malignant from benign cardiac tumors [15]. Computed tomography has also high sensitivity and specificity in diagnosing atrial thrombus so it can be useful in indentifying 'true mass' [16]. In our experi-

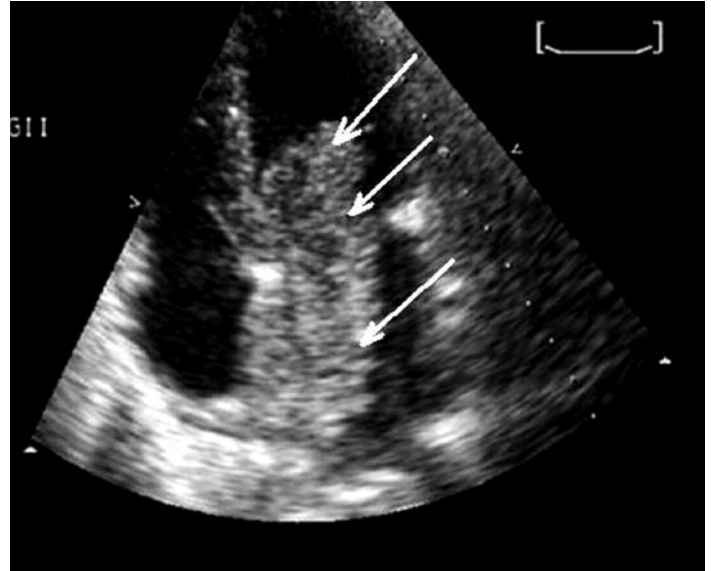

Figure 5. Myxoma of the left atrium, visualized by TTE

ence these additional methods proved to be helpful in cases of malignant tumors of the left atrium. Their relatively small size, greater rigidity and a complex anatomical relationship, suggesting infiltration of cardiac structures, were further confirmed histologically in the postoperative examination. In the analyzed material we found: leiomyosarcoma (1), myxosarcoma (1), fibrosarcoma (2), liposarcoma (1), thymoma (1) and non-small cell carcinoma (metastasis from the lung) (1 patient). In other reports besides the dominant proportion of myxomas, there were found a number of primary benign cardiac tumors such as lipoma, fibroma, fibroelastoma, etc., as well as several other malignancies, mostly metastatic [17-19]. Results of surgical treatment for benign tumors of the heart are very good. Usually, complete recovery can be obtained. Recurrences within 10-15 years of follow-up occur in approximately $1.5 \%$ of sporadic cardiac myxomas, and $12-$ $22 \%$ of patients with familial or complex form, which is confirmed by the authors of other reports $[20,21]$. Similar data concerned our patients, since relapses were noted in approximately $6 \%$ of cases of sporadic myxomas. In relation to primary malignancies, the possibility of radical excision, local spread of the tumor or its recurrence, expansive growth, and high incidence of metastases and the low effectiveness of adjuvant therapies (chemo-and radiotherapy) are the cause of unsatisfactory results of treatment. In our material, approximately $86 \%$ of the cases did not survive 1 year. Other authors suggest an even lower percentage of survival over 1 year [22], while radical resection of the tumor mass is achieved [23]. As many as $90 \%$ of patients with malignant tumors of the heart without surgical treatment died within an average of 9-12 months after diagnosis of the tumor [24]. While performing diagnostics and planning the cardiac tumor treatment, it should be borne in mind that metastases occur at least 40 times more often than primary lesions, mostly from lung cancer, breast cancer, lymphoma, leukemia, esophageal cancer, 
uterine cancer, malignant melanoma, renal cell carcinoma and liver or adrenal gland cancer [25]. However, in our experience metastatic tumors made up less than $30 \%$ of diagnosed malignant cardiac tumors.

In conclusion, short- and long-term results of surgical treatment of benign heart tumors such as myxoma are very good. Local recurrence of myxoma occurs extremely rare; however, its localization and structure are slightly modified, both in the echocardiographic and histopathological examination. Malignant cardiac tumors, although rare, have a poor prognosis. Malignant tumors have a characteristic echocardiographic presentation and intraoperative image, especially including their localization, size, mobility, attachment and anatomical relationships with the possibility of infiltrating the heart structures.

\section{References}

1. Castillo JG, Silvay G. Characterization and management of cardiac tumors. Semin Cardiothorac Vasc Anesth 2010; 14: 6-20.

2. Kapusta A, Lipiec P, Chrzanowski Ł, Foryś J, Kasprzak JD. Untypical cause of heart failure - right atrial myxoma [Polish]. Pol Arch Med Wewn 2007; 117: 470-2.

3. Kontogiorgi $M$, Exarchos D, Charitos $C$, et al. Primary right atrium angiosarcoma mimicking pericarditis. World J Surg Oncol 2007; 5: 120.

4. Yu K, Liu Y, Wang H, Hu S, Long C. Epidemiological and pathological characteristics of cardiac tumors: a clinical study of 242 cases. Interact Cardiovasc Thorac Surg 2007; 6: 636-9.

5. Butany J, Leong SW, Carmichael K, Komeda M. A 30-year analysis of cardiac neoplasms at autopsy. Can J Cardiol 2005; 21: 675-80.

6. Kocańda S, Rdzanek A, Filipiak KJ. Pierwotne nowotwory serca [Polish]. Forum Kardiologów 2000; 5: 65-73.

7. Shapiro LM. Cardiac tumors: diagnosis and management. Heart 2001; 85: 218-22.

8. Orlandi A, Ciucci A, Ferlosio A, Pellegrino A, Chiariello L, Spagnoli LG. Increased expression and activity of matrix metalloproteinases characterize embolic cardiac myxomas. Am J Pathol 2005; 166: 1619-28.

9. Kołacz J, Fedan A, Dziedzic P, Pasowicz M. Śluzak lewego przedsionka [Polish]. Choroby Serca i Naczyń 2005; 2: 229-31.

10. Alter P, Grimm W, Rominger MB, et al. Right ventricular cardiac myxoma. Diagnostic usefulness of cardiac magnetic resonance imaging. Herz 2005; 30: 663-7.

11. Irani $A D$, Estrera AL, Buja LM, Safi HJ. Biatrial myxoma: a case report and review of the literature. J Card Surg 2008; 23: 385-90.

12. Velicki L, Nicin S, Mihajlovic B, Kovacevic P, Susak S, Fabri M. Cardiac myxoma: clinical presentation, surgical treatment and outcome. J BUON 2010; 15: 51-5.

13. Tempe DK, Dutta D, Minhas $H$, et al. A rare case of myxoma in the right ventricular outflow tract extending to the pulmonary artery. Ann Cardiac Anaesthesia 2010 13: 167-8.

14. Motwani M, Kidambi A, Herzog BA, et al. MR imaging of cardiac tumors and masses: a review of methods and clinical applications. Radiology 2013; 268: 26-43.
15. Shao D, Wang SX, Liang CH, Gao O. Differentiation of malignant from benign heart and pericardial lesions using positron emission tomography and computed tomography. J Nucl Cardiol 2011; 18: 668-77.

16. Wu X, Wang C, Zhang C, et al. Computed tomography for detecting left atrial thrombus: a meta-analysis. Arch Med Sci 2012; 8: 943-51.

17. Veinot JP, Burns BF, Commons AS, Thomas J. Cardiac neoplasms at the Canadian Reference Centre for Cancer Pathology. Can J Cardiol 1999; 15: 311-9.

18. Piazza N, Chughtai T, Toledano K, Sampalis J, Liao C, Morin JF. Primary cardiac tumours: eighteen years of surgical experience on 21 patients. Can J Cardiol 2004; 20 1443-8

19. Perchinsky MJ, Lichtenstein SV, Tyers GFO. Primary cardiac tumors. Forty years' experience with 71 patients. Cancer 1997; 79: 1809-15

20. Turhan S, Tulunay C, Altin T, Dincer I. Second recurrence of familial cardiac myxomas in atypical locations. Can J Cardiol 2008; 24: 715-6.

21. Kanaan S, Nuno I. Atrial myxoma presenting as asthma in adolescent. Internet Journal Thoracic and Cardiovascular Surgery 2007; 8 (2).

22. Molina JE, Edwards JE, Ward HB. Primary cardiac tumors: experience at the University of Minnesota. Thorac Cardiovasc Surg 1990; 38: 183-91.

23. Simpson L, Kumar SK, Okuno SH, et al. Malignant primary cardiac tumors: review of a single institution experience. Cancer 2008; 112: 2440-6.

24. Neragi-Miandoab S, Kim J, Vlahakes GJ. Malignant tumours of the heart: a review of tumour type, diagnosis and therapy. Clin Oncol (R Coll Radiol) 2007; 19: 748-56.

25. Dąbek J, Twardowski R, Jakubowski D, Michniak B, Świderski R, Gąsior Z. Skuteczność leczenia guzów serca rozpoznanych $w$ klinice kardiologii $w$ siedmioletniej obserwacji [Polish]. Pol Merk Lek 2009; 27: 362. 